\title{
Manipulating happiness: Maria Montessori
}

\author{
Robert Biswas-Diener
}

\begin{abstract}
Maria Montessori is best known for her legacy as an educator. She is the founder of a system of schools that has achieved worldwide success. Instrumental to her teaching method is the idea of fostering engagement by offering children individual choice and harnessing intrinsic motivation. For this reason, she is nominated as a noteworthy felicitator or happiness-enabler. In this article, I discuss Montessori's life with a special emphasis on her teaching philosophy and methods. I briefly discuss psychological research as it relates to choice-related topics such as perceived personal control and autonomy. I also discuss some limitations of choice as an avenue toward happiness.
\end{abstract}

Keywords: Montessori, education, happiness, subjective wellbeing, subjective well-being, selfdetermination theory

\section{Introduction}

Imagine yourself in a different job from the one you currently have. Instead of going into computers, or social sciences, or marketing, or whatever your current profession is you instead chose to go into a field that flies in the face of all convention. Bullfighting, perhaps. Picture what it would be like as a newly minted college graduate to tell your parents that you were going to become a bullfighter. Imagine the humored and horrified reactions of your friends, the difficulties in finding a good bullfight school, and the hardship in acquiring funding to learn your new art. Entering a non-traditional profession is nothing short of courageous, and certainly also calls upon strengths such as perseverance, tolerance and patience. Think of the type of person who has the sense of adventure, spirit of single-minded purpose and willingness to undertake hardship that would enter such a non-traditional profession as bullfighting. Maria Montessori, founder of the well-known Montessori system of schools, is exactly such a person. She may not have been a matador, but she chose an unusual profession in which she could reasonably expect a great deal of criticism: medicine. Montessori was a professional pioneer: the first woman in Italy to receive training and a degree in medicine. It was her experiences in school-including the hostile hallways of her medical academy-that gave Montessori the initial insights into pedagogy, learning styles and cognitive development that would later form the seeds of her famous curriculum embodied in Montessori schools. Due to the worldwide proliferation of this school system, the unique methods at the heart of the so-called 'Montessori Method', and the documented success of graduates of these schools, I nominate Maria Montessori as an important felicitator or happiness-enabler.

I will present a brief overview of Montessori, the woman, as well as discuss her educational legacy. More crucially, however, I will focus on the intellectual heart of her pedagogy - free will and the intrinsic desire to grow-and link these to interdisciplinary happiness research and the topic of happiness in general. 
The legacy of Maria Montessori is far more than it might have been given the historical time in which she lived (1870-1952). As the first woman doctor in Italy she could have been confined easily to the annals of history as a landmark feminist. She could be noteworthy as a kind of medical Amelia Earhart; daring to tread where women had not gone earlier. If that had been the extent of Montessori's impact, that alone would have been interesting and important. But what makes the Maria Montessori story so special is that she turned her ambition toward others. Because of her personal experiences with educational hardship, Montessori dedicated herself to a lifetime of creating institutions that would help young people enjoy learning and, ultimately, become happier, more fulfilled, adults. In this sense Montessori was a sort of factory owner-although she would likely have been appalled at the metaphor-and her great machines rolled out civic-minded, creative and happy young people.

\section{Research on Montessori schools}

If you are anything like me you are probably reluctant to believe stories about one school system or another being the magic solution to everyone's educational needs. Indeed, it is in their desire and ability to look critically at educational policy and outcomes that professional education researchers differ from proud parents of schoolchildren. Montessori schools, like many educational systems, particularly those built around a charismatic leader, are often touted by the initiated as fresh, effective and beneficial in the long term. But these kinds of claims are commonly opinions and must be evaluated both systematically and scientifically. There is little question that Montessori was a pioneer, but can we really claim that her schools are better than those created by other charismatic educators, or even better than traditional public schools? To get a better sense of the actual differences between Montessori schools and their counterparts we have to look beyond the teachers, who might be biased, and the parents, who are similarly invested. We have to turn to science. Fortunately, there is research on the effectiveness of Montessori programs. In one study of a Montessori school in Milwaukee, Wisconsin (USA), for example, Lillard and Else-Quest (2006) were interested in both the academic and social outcomes of Montessori education. To investigate these outcomes they examined children who had participated in a school lottery; approximately half of whom were randomly selected into the Montessori system and the other half ended up in other types of schools. By using the lottery as a means of selection the researchers were able to rule out the pesky problem that educational benefits might have more to do with the types of families who enroll in Montessori schools rather than with the school itself. The researchers found that the young children in the study -5 year olds - showed equal performance as their control group peers on some tests of cognitive ability, and superior performance on others, such as recognizing letters and words. The Montessori kids also outperformed their counterparts on social and behavioral measures, and were better able to solve hypothetical social problems through the use of fairly sophisticated reasoning, such as discussing principles of justice and fairness. These results were not confined to the youngest pupils. Stories written by the Montessori 12 year olds who participated in the study were similar to those created by children in the control group in terms of spelling and grammar; however, they were judged as significantly more creative compared to the control 12 year olds. The real gains at the older age did not appear to be in academic prowess but in social ability. The Montessori 12 year olds were more likely to exhibit appropriate assertiveness and report feeling a stronger sense of community than kids in the control group. Lillard and Else-Quest conclude their study by pointing out that-at least in this single instance-the performance of Montessori children is comparable to that of children in other schools or, in many cases, superior. 
This conclusion dovetails with the least scientific study ever conducted of Montessori: I interviewed a single 4-year-old Montessori student, Ella. When I asked her "what makes you happy at school?" she answered, "Everything!" When I pressed her for specifics she was able to articulate a list of three happiness-producing aspects of her Montessori curriculum: playing, hot lunch, and work. That's right, work. "Work" is the name that the Montessori students and teachers give to a wide range of educational activities, from feeding and playing with classroom animals to washing dishes to manipulating shape and color blocks. One Montessori teacher I interviewed told me that using the term 'work' to describe the children's activities lends a sense of dignity and importance to what they do, and set up kids for a lifetime of believing that work can be fun, rewarding, and educational. "Adults," the teacher told me, "tend to work to manipulate their environment while children tend to work to manipulate themselves. It is a developmental process." When I asked Ella what, specifically, she enjoyed about "work" her answer was immediate, "I like that it is challenging."

Either Ella is being fed some excellent propaganda or she is participating in a school system which fosters enjoyment alongside learning. Which begs the tough question: Was Maria Montessori a happiness-enabler? Despite her many personal achievements we cannot simply take for granted that she has substantively increased the happiness in the world. She's made a contribution in the form of helping kids learn, but has she actually made anybody happy? We have strong evidence that Montessori created positive reforms within education, and established an educational infrastructure that fosters an on-going and active learning community (Lillard, 2005). For this alone, I think we can reasonably say that she provided enabling conditions that set the stage for happiness. Certainly, Montessori teachers and parents will attest to the fact that they have often seen their students and children happy as a direct result of the school's teaching methods. Still, detractors might argue that one can find happy children in virtually every school. Ultimately, the question of Montessori's happiness legacy is an empirical issue, subject to scientific testing. There is, in fact, an entire book on the psychological science undergirding Montessori's methods (Lillard, 2005). It is an excellent guide to the motivation, cognition and developmental research literature relevant to Montessori's teaching methods. Lamentably, there is no mention of joy, satisfaction or happiness in the index. The studies presented within the book use typical measures of academic performance such as reading ability and this overview covers little about the children's actual experience of their learning. One notable exception to this is a study by Rathunde and Csikszentmihalyi (2005), the latter being the 'positive psychologist' best known for his pioneering work on 'flow' (Csikszentmihalyi, 2008), the state colloquially known as 'being in the zone.' In the 2005 study the researchers found that Montessori students' reports of their day-to-day experience were significantly more positive than ratings offered by students in traditional educational settings. Although this is a single study and cannot, therefore, be generalized to all Montessori students throughout the world, it is a first step; indeed it is a suggestive piece of tangible evidence that Montessori was not just concerned with reading and arithmetic, but also with processes and happiness. Ultimately, personal fulfillment will be the charge of each student as he or she leaves the halls of Montessori school and heads out into the world. Their job will likely be - at the very least-a little bit easier owing to the fact that Montessori removed obstacles to both wellbeing and learning and also created structures that support growth, mastery, independence and other psychological needs that are strongly associated with happiness.

It is important, at this point, to bring up a criticism not only of the Montessori approach but of the idea of educating for happiness in general. While the notion of wellbeing-producing 
institutions fits well with the modern positivity movement, there are those who rightly suggest caution in this regard (e.g. Ehrenreich, 2009). It is wise to reflect on the fundamental purpose of education. Historically, philosophers have understood education to be, in part, about influencing character, virtue and morality (e.g. Aristotle, $4^{\text {th }}$ Century BCE/1987); and many are inclined to agree with the idea that the state has both opportunity and obligation to intervene in public moral discourse (e.g. Smith, 1776/1987). There are those who disagree, however, on the basis that government intrusion into mental states is overstepping authoritative bounds and could be a form of violence against individual liberty. Critic Kathryn Ecclestone (2004), for example, argues that the heavy emphasis on self-esteem as a desirable goal of education is more aligned with therapeutic modalities than educational policy. Similarly, Ecclestone and Field (2003) make the case that emphasizing social capital variables as foci of educational policy contains potential drawbacks; among these is the possibility that normative social policy could undermine the performance of, or punish, non-conformists. Certainly, this point would be interesting to consider in the context of the Montessori classroom: how are non-conformists dealt with? What happens to those children who do not exhibit the capacity for 'work' or who would prefer not to choose for themselves? Unfortunately, no research on this topic exists (to the best of my knowledge). This absence highlights the fact that the research literature on Montessori schools is small, which is surprising given the fact that there are more than 7,000 Montessori schools.

\section{The life that led to the legacy}

The theme of 'challenge' that 4-year-old Ella described was a concept familiar to the founder of the Montessori schools. Maria Montessori was born in Italy in 1870, the same year that country was first officially united in modern times. From the perspective of a biographer, her childhood was largely unremarkable. Perhaps the most interesting and ironic footnote from her formative years is that, when considering a future profession, Montessori indicated an interest in becoming "anything but a teacher" (Kramer, 1976/1988: 23). Her experiences in school were discouraging, to say the least. She was actively dissuaded from cultivating her natural gifts for mathematics and, defying her parents, entered first a boy's technical school and later medical school. There were no female doctors in Italy at the time and her conspicuous appearance in the hallways and lecture theaters of the medical school was discomfiting to many. She was often ostracized by her all-male peers, many of whom would jeer at her in the concourses as she passed by. Montessori was also not allowed to dissect bodies with her classmates as it was deemed unseemly by contemporary standards for a woman to do so in the presence of men. Although the years of her higher education were undoubtedly socially difficult for Montessori, her efforts paid off and she eventually became the first female medical doctor in Italy (Standing, 1957/1998).

After completing her medical training Montessori assumed the position of assistant director of the psychiatric clinic attached to the University of Rome. It was in this capacity that she had her first opportunities to visit with and observe institutionalized children. As you might imagine, the psychiatric care in the facilities at the turn of the century were not up to modern standards. Ever prescient, Montessori was quick to notice that the conditions in which the children were housed-the lack of toys, objects or other forms of stimulation-were substandard to the degree that she believed it would interfere with any potential cognitive development. She quickly became an advocate for better education for these institutionalized children, arguing - in a speech on 'moral education' delivered in 1899 (Standing, 1957/1998) that they should be entitled to 'normal' instruction. In this way and from this time Montessori 
gravitated from being a practicing physician and lecturer to becoming an education reformer. Her leaning toward social reform was consistent with the times: at the turn of the twentieth century Italy was in the midst of social and economic crisis following a widespread crop failure, repressive government policies and heated public discourse over the contentious political issue of colonization in Africa (Kramer, 1976/1988). Then-Prime Minister Giolitti came to power in 1906 promising sweeping reforms for the poor, and these paved the way for Montessori's ideas on education to become reality.

It is interesting that Montessori had strong opinions on how to improve education but no actual school in which to implement them. It was this lack of formal institutional affiliation that eventually led her to a slum school in Rome-the now famous Casa dei Bambini (Children's House)-where she found a testing ground for her theories and where she refined her methods. Because Casa dei Bambini was a slum school catering to Rome's disenfranchised children, Montessori had an opportunity to implement teaching reform with a disadvantaged population that, in essence, made her educational methods a form of social activism (Kramer, 1976/1988). The school also gave Montessori a laboratory for observing the natural behaviors of 'normal' children and experimenting with methods for engaging them in the learning process. The success of her school was evident early on and her model was quickly expanded to other schools, and Montessori continued to craft her program and implement it in schools throughout the world until her death in 1952.

Montessori's legacy is much larger than the humble origins of her first school though. Currently, there are about 7,000 Montessori schools around the world and innumerable independent Montessori-inspired institutions. These schools ensure that Montessori's mission to cultivate self-motivated, socially aware and responsible citizens is both widespread and enduring. Her name and methods also influence books, conferences, and teacher training institutions. She was nominated for the Nobel Peace Prize on three separate occasions, but it was never awarded to her. Although she is principally known as an educator, Montessori was, at heart, a social reformer and activist and often addressed spiritual, feminist and other socially active groups. In fact, she thought of herself as a "Social Crusader" (Montessori, 2008; p. 57).

Perhaps her greatest achievement, and the primary reason I nominate her as one of history's great felicitators, is the effect she has had on the world through her students, numbering in the hundreds of thousands at least. Montessori wanted to teach children more than facts; she wanted to encourage good character. Although the law of averages tells us that we can find famous alumni in any school system, I would be remiss if I did not point out a few notable Montessori graduates: Amazon.com founder Jeff Bezos was educated at Montessori, as were Anne Frank, Julia Child, and Nobel laureate Gabriel Garcia Marquez. It could be that these people would have grown up to be famous whatever their educational background, of course, but it is more amusing to think that the Montessori system had something to do with the rise of its graduate Sean 'Puff Daddy' Combs. Montessori (2009) believed that children had a psychological hunger for exploring and learning about the world, and only by satisfying this need from within could good character be developed. She was passionate about helping each individual child to live a life that was engaged, meaningful and enjoyable. These are, by their very nature, vital components of happiness.

\subsection{Time out: A peek into a Montessori classroom}

If you were to enter a Montessori classroom, especially an early childhood education classroom, you might notice several differences between it and the typical public school classroom. For instance, if you saw the early childhood education classroom at the Montessori 
School of Ladera Ranch, California, you might notice the animals. Maria Montessori believed that animals were helpful to teach children responsibility and connection. The early childhood education room at Ladera Ranch boasts a rabbit, a leopard gecko, two beta fish, hermit crabs, a tiger salamander and a turtle named 'Sophie', as well as outdoor feeders for hummingbirds and finches. You might also notice that all of the fixtures in the room are small, built at the children's eye level.... nod to the legitimacy and importance of being young. You would also likely notice the many materials stacked and shelved against the walls. These materials, sometimes called 'manipulatives' are, in some ways, the core elements of the Montessori approach to learning. They include, among other things, alphabet blocks for reading, beads for counting and sorting, a pig - that's right, a pig - for washing. Washing a toy pig is seen as an element of life skills training as it points student attention to hygiene and caretaking. When I interviewed teacher Indi Avila she told me that these manipulatives were the most surprising aspect of Montessori:

I attended Montessori from the age of four to when I was six and the materials in my classroom now are the same as those from when I was a kid! I can remember doing the same things my students are, like pouring rice from jar to jar. (Personal communication)

These tactile materials hearken back to the time of Maria Montessori herself and her observations that institutionalized children hungered for stimulating materials. Maria Montessori wrote about a time when she found such a child playing with food crumbs, just to have something to play with at all. Back at Ladera Ranch, teacher Karen Skirvin also emphasized that the materials are chosen with care to teach the children how to interact with the world and to cultivate an appreciation for beauty. She told me that her two- and three-yearold students do not drink from plastic cups but, rather, from glass and ceramic containers. When I asked what would happen in the all-too-likely event that such a vessel were dropped she smiled and said, "Then the children would learn about what happens to glass when it hits the floor."

The Montessori school day begins outdoors on the playground, as students are dropped off. The teachers are aware that this period-often thought of as the minutes before school begins -is actually a time of interaction and learning. From the playground the students file into the classroom where they have, at least in the case of the younger children, 'circle time'. Circle time is a transition period of sorts, to help the kids shift from physical play mode to indoor mode. The children acknowledge one another, greet their instructors, say good morning to the class pets and then move into 'work'. It is here that the children have the opportunity to express personal preferences and follow their own whims and intuition. Rather than following a structured, teacher-centered curriculum, the Montessori students are allowed to gravitate toward whichever projects they happen to fancy on a particular day. This ensures the students are self-motivated in their learning. When I expressed concern that a student could, potentially, choose to engage in counting and sorting activities day after day while ignoring reading readiness activities, teacher Indi Avila reassured me: "That is what the teachers are for-to gently guide the children." This is also when Indi pointed out something I, or any casual visitor, might not notice. All the materials are arranged in order of difficulty and complexity from left to right and top to bottom on the shelves, thus preparing the unwitting children for the structure of reading when they arrive to that stage of education. 


\section{Freedom: The heart of Montessori education}

Maria Montessori came to believe that people-everyone, and especially children-have an innate desire to learn. In part, this conclusion was the result of her observation of institutionalized youth, who hungered for stimulation and, later, from her observations of children in her own schools. Montessori thought of curiosity as a human birthright that people employ on a daily basis to motivate action and engage with the world. To this end, she advocated a system of learning that was 'student focused,' with children's interest pouring forth from within, rather than the traditional passive learning methods in which children are expected to sit, listen and be good receptors of content. This is aligned with research findings that suggest that extrinsic reinforcement undermines enjoyment, especially in the case where tasks would have been inherently interesting without reinforcement (Lepper, Greene \& Nisbett, 1973). Montessori's approach to learning was built on a foundation of personal choice. According to Edwards (2006), Montessori:

[S]trongly believed that all young children naturally prefer to learn in an organized but supportive environment that permits a high degree of choice, control, and self-direction, and where children are not distracted by extrinsic rewards and punishments that distort their preferences (for instance, by grades, stars, awards, demerits, honor rolls, smiley faces, and the like) (p. 184).

Just as adults are free to gravitate toward skiing or gambling or woodworking as suits their fancy, Montessori believed that children should have some say in what type of educational activities they spend time on.

Although Montessori did not have the sophisticated science of modern times at her disposal, it turns out that a huge range of recent research supports her instincts about children. In fact, if Montessori schools can be thought of as small-scale societies, then it would be interesting to know to what extent freedom is associated with happiness at the societal level. Fortunately, there are data on exactly this topic. In a study of factors predicting the wellbeing of nations, for example, researchers found that social equality, human rights and individualism were significant predictors of wellbeing (Diener, Diener \& Diener, 1995). Even when controlling for other factors, such as income, individualism reliably predicted societal happiness. Diener, Diener and Diener (1995) also evaluated the outcomes associated with democracy (and increasing democratization of a country), and found a strong relationship between democracy and happiness. However, the authors of this work also point out that democracy is neither necessary nor sufficient for societal-level happiness. In a more direct assessment of economic, political and personal freedom, Veenhoven (2000) found that greater freedoms were significantly related to higher levels of happiness across societies. In a study using data from the Gallup World Poll, a survey that assessed the happiness of more than 140,000 respondents in 125 countries, Helliwell and his colleagues (2010) found that 'freedom to choose' was a significant predictor of happiness. These studies all point to the same conclusion: societies higher in democratic rights and personal freedoms appear to be happier places. Certainly, we must ask about the direction of the causal arrow; it could be, for example, that happier people are more likely to create societies which offer more freedoms. In addition, the question of freedoms must be disentangled from the wealth of nations. It could be, for instance, that democratic nations happen to have economic systems that produce more wealth, and therefore the happiness of the citizenry might better be accounted for by public infrastructure and other material concerns rather than individual freedoms. Fortunately, we can employ statistical controls to parse out the relative effects of income. Although studies that adopt this tack differ 
slightly from one another, the consensus view is that - at the societal level - freedoms matter to happiness more than do the contributions of national wealth (Helliwell et al., 2010; Veenhoven, 2005). In the end, groups - whether they are nation-states or Montessori classrooms - seem to produce happier members when they are structured around individual freedom and choice.

Not only have researchers discovered in large-scale surveys that freedom is associated with happiness but it is also related to happiness at the individual level. Research on choice behaviors, such as how people decide to spend their money, suggests that some choices pay higher 'happiness dividends' than others. Van Boven (2005), for example, found that people who spend money on experiential rather than material purchases tend to be happier. Similarly, Aknin and colleagues (2010) found that people who spend money on others are happier than those who spent a comparable amount on themselves. This finding has been replicated in societies across the world (Aknin et al., submitted). This body of research suggests that people are free to spend on the goods and services that are most attractive to them personally (a form of economic freedom) but that, where personal happiness is concerned, some choices will be better than others. Interestingly, it may be that we are biologically predetermined both to help others and to adapt to new circumstances. If this is the case then expenditures on others and on experiences (to which we are less able to adapt than we are to expenditures on material items) - those purchases that are the most emotionally rewarding-are actually in line with our basic phenotypic motives. The message is that we may be free to make any choices we want, but we will be rewarded - both emotionally and socially - for only some of them.

Another line of research connecting freedom to choose and the happiness of individuals is that which examines personal control. Thompson (2002) argued that humans are unique in the extent to which they can manipulate their environment and judge the degree to which they have the means to do so. This is certainly a sentiment with which Maria Montessori would have agreed-she believed that manipulating the environment was a primary adult longing (Montessori, 1966). Thompson suggests that a sense of control may activate problem solving behaviors and increase perseverance. Grob (2000) has found that people who believe they have more control of their environment are, in fact, happier. There is also a substantial research literature on the relation between income and subjective wellbeing suggesting that there is a modest positive correlation between the two, perhaps explained-in part-by the suggestion that more affluent individuals have a greater ability to fund the pursuit of personal goals (Diener \& Biswas-Diener, 2002). Although there are many studies that hint at the possibility that having personal control and free choice are important to individual and group happiness, these do not really tell us-psychologically-why freedom and control might be associated with happiness. For that, we have to dig a little deeper.

\section{The psychology of autonomy}

The strong links between freedom, personal control and happiness suggest that people generally fare well when they are autonomous. Cultural critics, on the other hand, remind us that - at best-we are interdependent creatures living in family groups and complex societies. The emphasis on the importance of social connectedness and cooperation extends especially to the classroom environment (Aronson, 1978). We are, after all, primates and have a natural tendency to cluster together in groups and rely on one another to get by. We live in an age where, worldwide, urban dwellers outnumber people living in rural locations. In fact, instances of reclusive people living in the geographic hinterlands are relatively rare. It appears, if anything, that folks like to work, live and play together. Which begs the question: what are the differential contributions of autonomy and relatedness to happiness? Which aspect of the 
Montessori school curriculum is the magic potion that leads to so much wellbeing? Is it that Montessori schools are viewed as a community, and tend to promote the strong bonding of children and teachers? Or is it that there is an emphasis on individual mastery? Or, perhaps, is there some optimal balance between the two?

Self-determination theory, advanced by Deci and Ryan (2000), contains the idea that there are three distinct and fundamental human needs. By needs I-and presumably Deci and Ryan-mean motives that drive just about everyone because they are so fundamental to our functioning, and so enjoyable when they are met. These three needs include autonomy, relatedness, and mastery. According to self-determination theorists people will be happy to the extent that they are gaining new skills, have the opportunity to express their unique selves, and have a chance to connect with others. Indeed, research supports this conclusion. Students in law school, for example, are happier and perform better when they are given more autonomy and steered away from a competitive attitude that might interfere with their ability to connect with their peers (Sheldon \& Krieger, 2007). Other studies have shown that having friends is a reliable predictor of happiness (Diener \& Seligman, 2002). This type of wellbeing research that focuses on psychological drive states rather than emotional pleasantry is often termed 'eudaimonic', from Aristotle's discussion of Eudaimonia-a state of wellbeing in which a person has achieved their highest potential (Aristotle $4^{\text {th }}$ Century BCE/1987).

Another eudaimonic course of research on 'psychological wellbeing' dovetails nicely with studies on self-determination theory. Ryff and Singer (1998) proposed that there are six fundamental human needs, and that progress toward and the fulfillment of these needs will equate with wellbeing. The needs associated with psychological wellbeing are self-acceptance, positive relations with others, autonomy, environmental mastery, purpose in life, and personal growth. These contain some overlap with those offered by self-determination theorists but include others, such as self-acceptance, as well. Like self-determination theory studies, studies on the fulfillment of needs associated with psychological wellbeing are generally associated with greater levels of happiness.

Where Maria Montessori and her methods are concerned, there is reason to believe that each of these needs is actively cultivated in the children who attend her schools. It may be that the unique techniques employed at Montessori schools are well-suited to promoting a sense of self-acceptance in children, or connectedness, or mastery.

\section{The limits of freedom}

The empirical evidence for the benefits of personal choice and freedom-related variables on wellbeing and healthy functioning are clear. They are, however, not the whole picture. There are several instances in which greater choice does not necessarily translate to higher wellbeing. All such instances are-to a greater or lesser degree-anchored in culture. In the first instance, an emphasis on extreme individualism can result in an expectation that people should have nearly unlimited choice. Western markets, especially those in the United States, follow this assumption. Schwartz $(1994 ; 2000)$ argues that there can be a 'tyranny in freedom' such that too much choice can undermine enjoyment. A classic real-world example of this is being stuck in traffic: if there is only a single lane of traffic you are mildly irritated by the lack of progress. If there are two or three lanes of traffic, however, you are more likely to be really angry - perhaps even at yourself-for choosing the 'wrong lane'. Thus, choice can be helpful, but when something goes wrong there is a natural tendency to blame one's self. Another cultural instance of the downsides of choice is that of collectivist cultures, where the individual is encouraged to subjugate their personal desires if those desires are perceived to come into conflict with the 
overall welfare of their in-group (Triandis, 1998). A final aspect of culture relates to basic cultural worldviews about the extent to which one has control over one's fate. Westerners tend to have a 'disjoint agency' view in which they have agency and therefore tend to take credit for successes and blame themselves for failures (Markus, Uchida, Omoregie, Townsend, \& Kitayama, 2006). Thus, there appears to be an optimal level of perceived personal control and freedom of choice, especially where happiness is concerned. Research is needed to examine the extent to which classroom choice is important both to learning and to enjoyment.

\section{Montessori today}

Maria Montessori died May 6, 1952 at the age of 81. Her legacy lives on in the thousands of Montessori and Montessori-inspired schools that exist on all six inhabited continents. Her name is a household word, and her life's mission offers the scenery for many interesting historical footnotes. Jean Piaget, for instance, conducted his famous observations of children in Montessori schools. Alexander Graham Bell helped to establish the first Montessori school in the United States. Montessori's influence is so great, in part, because of the inherent effectiveness and popular appeal of her views on educating children. Although her methods have been applied primarily to the education of younger children it is possible that her experiential approach and her emphasis on student choice are appropriate in higher education as well (Biswas-Diener \& Patterson, in press). But more than that, Montessori was a pioneer who faced challenges and charted new intellectual territory. Although her scientific methods are antiquated by today's standards, her far-sightedness is unquestionable. Ultimately, Montessori provides a personal example of happiness: fostering relationships by realizing one's responsibility to others; enjoying mastery by working within areas of strength; and having the courage to live a life that is independent enough to provide opportunities to live one's values and progress toward personally relevant goals. She wasn't exactly a bullfighter, but her life was just as powerful and dynamic.

\section{Author}

Robert Biswas-Diener

Portland State University

biswasdr@pdx.edu

\section{Publishing Timeline}

Received 4 February 2011

Accepted 22 March 2011

Published 20 July 2011

\section{References}

Aknin, L., Dunn, E., Helliwell, J., Biswas-Diener, R., Kemeza, I., Nyende, P., Ashton-James, C., \& Norton, M. (Submitted). Prosocial spending and well-being: Cross-cultural evidence for a psychological universal.

Aknin, L., Sandstrom, G., Dunn, E., \& Norton, M. (2010). Investing in others: Prosocial spending for (pro)social change. In R. Biswas-Diener (Ed.), Positive psychology as social change. Dordrecht, Netherlands: Springer.

Aristotle. (1987). Nicomachean ethics. New York: Macmillan. (Original work published 4th Century BCE). Aronson, E. (1978). The jigsaw classroom. Thousand Oaks, CA: Sage.

Biswas-Diener, R., \& Patterson, L. (in press). An experiential approach to teaching positive psychology to undergraduates. Journal of Positive Psychology. 
Csikszentmihalyi, M. (2008). Flow: The psychology of optimal experience. New York: Harper Perennial.

Deci, E.L., \& Ryan, R.M. (2000). The 'what' and 'why' of goal pursuits: Human needs and the selfdetermination of behavior. Psychological Inquiry, 11, 227-268. http://dx.doi.org/10.1207/S15327965PLI1104 01

Diener, E., \& Biswas-Diener, R. (2002). Will money increase subjective well-being? Social Indicators Research, 57, 119-169. http://dx.doi.org/10.1023/A:1014411319119

Diener, E., Diener, M., \& Diener, C. (1995). Factors predicting the subjective well-being of nations. Journal of Personality and Social Psychology, 69, 851-864. http://dx.doi.org/10.1037/0022-3514.69.5.851

Diener, E., \& Seligman, M.E.P. (2002). Very happy people. Psychological Science, 13, 81-84. http://dx.doi.org/10.1111/1467-9280.00415

Ecclestone, K. (2004). Learning or therapy?: The demoralisation of education. British Journal of Educational Studies, 57, 127-141.

Ecclestone, K., \& Field, J. (2003). Promoting social capital in a 'risk society': A new approach to emancipatory learning or a new moral authoritarianism? British Journal of Sociology of Education, 24 (3), 267-282. http://dx.doi.org/10.1080/01425690301895

Edwards, C.P. (2006). Montessori education and its scientific basis. Applied Developmental Psychology, 27, 183-187. http://dx.doi.org/10.1016/j.appdev.2005.12.012

Ehrenreich, B. (2009). Bright-sided: How the relentless promotion of positive thinking has undermined America. New York: Picador.

Grob, A. (2000). Perceived control and subjective well-being across nations and across the life span. In E. Diener \& E.M. Suh (Eds.), Culture and subjective well-being, 319-339. Cambridge, MA: MIT Press.

Helliwell, J., Barrington-Leigh, C., Harris, A., \& Huang, H. (2010). International evidence on the social context of well-being. In E. Diener, J. Helliwell \& D. Kahneman (Eds.), International differences in wellbeing, 291- 325. Oxford, UK: Oxford University Press.

Kramer, R. (1976/1988). Maria Montessori: A biography. Cambridge, MA: De Capo Press.

Lepper, M.R., Greene, D., \& Nisbett, R.E. (1973) Undermining children's intrinsic interest with extrinsic reward: A test of the "overjustification" hypothesis. Journal of Personality and Social Psychology 28 (1), 129-137. http://dx.doi.org/10.1037/h0035519

Lillard, A. (2005). Montessori: The science behind the genius. Oxford, UK: Oxford University Press.

Lillard, A., \& Else-Quest, N. (2006). Evaluating Montessori education. Science, 313, 1893-1894. http://dx.doi.org/10.1126/science.1132362

Markus, H.R., Uchida, Y., Omoregie, H., Townsend S.S.M., \& Kitayama S. (2006). Going for the gold: Models of agency in Japanese and American contexts. Psychological Science, 17, 103-112. http://dx.doi.org/10.1111/j.1467-9280.2006.01672.x

Montessori, M. (1966). The secret of childhood. New York: Ballentine.

Montessori, M. (2008). The Montessori Method. BN Publishing.

Montessori, M. (2009). The absorbent mind. BN Publishing.

Rathunde, K. \& Csikszentmihalyi, M. (2005). Middle school students' motivation and quality of experience: A comparison of Montessori and traditional school environments. American Journal of Education, 11, 341-371. http://dx.doi.org/10.1086/428885

Ryff, C.D., \& Singer, B. (1998). The contours of positive human health. Psychological Inquiry, 9, 1-28. http://dx.doi.org/10.1207/s15327965pli0901 1

Schwartz, B. (1994). The costs of living: How market freedom erodes the best things in life. New York, NY: Norton.

Schwartz, B. (2000). Self Determination: The tyranny of freedom. American Psychologist, 55, 79-88. http://dx.doi.org/10.1037/0003-066X.55.1.79

Sheldon, K., \& Krieger, L. (2007). Understanding the negative effects of legal education on law students: A longitudinal test and extension of self-determination theory. Personality and Social Psychology Bulletin, 33, 883-897. http://dx.doi.org/10.1177/0146167207301014

Smith, A. (1776/1987). The wealth of nations. The Great Books (Vol. 39). Chicago: Encyclopedia Britannica. Standing, E.M. (1957/1998). Maria Montessori: Her life and work. New York: Plume. 
Thompson, S.C. (2002). The role of personal control in adaptive functioning. In C.R. Snyder \& S. Lopez (Eds.), Handbook of positive psychology, 202-213. Oxford, UK: Oxford University Press.

Triandis, H. (1998). Individualism and collectivism. Boulder, CO: Westview Press.

Van Boven, L. (2005). Experientialism, materialism, and the Pursuit of Happiness. Review of General Psychology, 9, 132-142. http://dx.doi.org/10.1037/1089-2680.9.2.132

Veenhoven, R. (2000). Freedom and happiness: A comparative study in forty-four nations in the early 1990s. In E. Diener \& E. M. Suh (Eds.), Culture and subjective well-being, 257-288. Cambridge, MA: MIT Press.

Veenhoven, R. (2005). Is life getting better? How long and happy do people live in modern society? European Psychologist, 10, 330-343. http://dx.doi.org/10.1027/1016-9040.10.4.330 